\title{
BMJ Open Parental experiences of end of life care decision-making for children with life- limiting conditions in the paediatric intensive care unit: a qualitative interview study
}

\author{
Sarah Mitchell, ${ }^{\circledR 1}$ Jenna L Spry, ${ }^{\odot 2}$ Emma Hill, ${ }^{2}$ Jane Coad, ${ }^{3}$ Jeremy Dale, ${ }^{\oplus}$ \\ Adrian Plunkett ${ }^{2}$
}

To cite: Mitchell S, Spry JL, Hill E, et al. Parental experiences of end of life care decision-making for children with life-limiting conditions in the paediatric intensive care unit: a qualitative interview study. BMJ Open 2019;9:e028548. doi:10.1136/ bmjopen-2018-028548

- Prepublication history and additional material for this paper are available online. To view these files, please visit the journal online (http://dx.doi org/10.1136/bmjopen-2018028548).

Received 13 December 2018 Revised 26 March 2019 Accepted 3 April 2019

Check for updates

(C) Author(s) (or their employer(s)) 2019. Re-use permitted under CC BY-NC. No commercial re-use. See rights and permissions. Published by BMJ.

For numbered affiliations see end of article.

Correspondence to

Dr Sarah Mitchell;

sarah.j.mitchell@warwick.ac.uk

\section{ABSTRACT}

Objectives To provide an in-depth insight into the experience and perceptions of bereaved parents who have experienced end of life care decision-making for children with life-limiting or life-threatening conditions in the paediatric intensive care unit (PICU).

Design An in-depth qualitative interview study with a sample of parents of children with life-limiting or lifethreatening conditions who had died in PICU within the previous 12 months. A thematic analysis was conducted on the interview transcripts.

Setting A PICU in a large National Health Service (NHS) tertiary children's hospital in the West Midlands, UK.

Participants 17 parents of 11 children who had died in the PICU.

Results Five interconnected themes were identified related to end of life care decision-making:(1) parents have significant knowledge and experiences that influence the decision-making process.(2) Trusted relationships with healthcare professionals are key to supporting parents making end of life decisions.(3) Verbal and non-verbal communication with healthcare professionals impacts on the family experience.(4) Engaging with end of life care decision-making can be emotionally overwhelming, but becomes possible if parents reach a 'place of acceptance'. (5) Families perceive benefits to receiving end of life care for their child in a PICU.

Conclusions and implications The death of a child is an intensely emotional experience for all involved. This study adds to the limited evidence base related to parental experiences of end of life care decision-making and provides findings that have international relevance, particularly related to place of care and introduction of end of life care discussions. The expertise and previous experience of parents is highly relevant and should be acknowledged. End of life care decision-making is a complex and nuanced process; the information needs and preferences of each family are individual and need to be understood by the professionals involved in their care.

\section{INTRODUCTION}

Improvements in survival associated with advances in medical therapy have resulted in
Strengths and limitations of this study

- Improving end of life care decision-making for children with life-limiting and life-threatening conditions in paediatric intensive care unit (PICU) is a pressing concern.

- This in-depth qualitative interview study provides insights into such decision-making from a parental perspective.

- The study was conducted with parents whose children had died from a range of different conditions.

- The qualitative nature of the study provides detailed, in-depth insights and an understanding of the parental experience of end of life care decision-making in PICU; however, recruitment was challenging and the number of participants is relatively small.

- The findings are relevant across a range of healthcare settings as the number of children with life-limiting and life-threatening conditions increases and more high-profile cases receive attention from the media.

increasing numbers of children and young people (hereafter described as children) living with life-limiting and life-threatening conditions. $^{12}$ Uncertainty is part of daily life for many of these children and their families, with a constant risk of sudden and unpredictable deterioration leading to the need for emergency medical care, admission to the paediatric intensive care unit (PICU) and the possibility of dying. Over $50 \%$ of children who die in England have a pre-existing life-limiting condition, ${ }^{34}$ and the most frequent place of death is PICU, commonly following the withdrawal of life-sustaining treatments. $^{5} 6$ The time spent on PICU before death is increasing, ${ }^{7}$ reflecting a trend towards longer attempts to sustain life. At times, parents and professionals may disagree about the indication for ongoing 
life-sustaining treatments, as illustrated in several recent high-profile cases. ${ }^{89}$

End of life care decision-making for children is complex. Furthermore, the provision of specialist paediatric palliative care services is currently inconsistent. ${ }^{10}$ Advance care planning (ACP) is advocated as a process that may help patients and families achieve a sense of control around their treatment choices towards the end of their child's life. ${ }^{11}{ }^{12}$ ACP is a core element of national palliative care strategies for both children and adults, ${ }^{13-15}$ and is included in the National Institute for Health and Care Excellence) quality standards for end of life care in infants, children and young people. ${ }^{14}{ }^{15}$ However, the current evidence base to inform policy and practice in end of life care decision-making for children, including ACP, is scarce. ${ }^{1216}$

\section{Aim of the study}

This study was designed to provide in-depth insights into the experiences and perceptions of parents who had experienced end of life care decision-making for their children with life-limiting or life-threatening conditions in PICU.

\section{Patient and public involvement}

Two bereaved parents joined the study team as patient and public involvement (PPI) advisors to ensure that the study design and outputs were relevant to their experience, one of whom has coauthored this paper. PPI was integral to the design of the study, including the wording of participant information sheets and interview schedule. Communication with PPI team members took place throughout the study via email (their expressed preference).

\section{METHODS}

The study protocol, which outlines the ethical issues raised by the study and the plans made to address these, is provided as online supplementary file 1 .

\section{Study setting}

The study setting was PICU at Birmingham Children's Hospital, a large tertiary referral centre in the West Midlands, UK. The PICU has 31 beds and manages approximately 1400 admissions per year. At the time of the study, the hospital palliative care team comprised two specialist nurses and a bereavement team. PICU was supported by a family liaison team. There was no standardised referral process to the palliative care team.

\section{Recruitment}

Participants were recruited purposively; all participants were bereaved parents of children with a pre-existing life-limiting condition who had died in PICU. Potential participants (those who were legally the parents or guardians of the child) were identified (by AP and JS) from the PICU mortality database retrospectively for a period of 12 months prior to study commencement and then prospectively over a 12-month period. Exclusion criteria were parents who were unwilling or unable to provide informed consent in English; bereaved parents of a child who had died from acute illness or trauma and parents aged 16 years or less at the time of recruitment.

Retrospectively, 59 cases of death in PICU were identified as suitable for approach; 58 letters were posted, one was sent by email (as the parents were participating in an email discussion about bereavement follow-up). There were 11 responses. Eight were positive, and led to interviews. Two declined to participate without further explanation. One letter was returned to sender.

Over the 12-month study period, 29 deaths were identified. The approach to the parents of these children was made at the time of invitation to bereavement follow-up, by letter, within 6 weeks of the child's death. Five positive responses were received which led to interviews.

Explicit decline was only stated in two retrospective replies. No specific reason was stated in either case. If there was no reply to the invitation, non-participation was assumed. The shortest time (for both retrospective and prospective approaches) between bereavement and interview was 7 months (average time 11.8 months, median=10 months).

\section{DATA COLLECTION Interviews}

A semi-structured interview schedule was devised to elicit in-depth details and reflections about end of life care decision-making in PICU, including experiences and perceptions of ACP (table 1). This was piloted with the PPI parents. Participants were offered a choice of face-toface or telephone interview. Interviews were conducted with either parent, separately or together, according to their preference. A distress protocol was developed for the interviews (see online supplementary file 1: research protocol) and all participants had access to support from the hospital bereavement team.

\section{Data analysis}

All interviews were transcribed verbatim. Data were managed using NVivo software. Thematic analysis of transcripts and field notes was carried out using an inductive approach as described by Braun and Clarke. ${ }^{17}$ This began with familiarisation with the data, reading and rereading the transcripts and coding the complete dataset. Three members of the study team independently coded a selection of transcripts (JS, AP and SM). Coding was discussed and compared at regular intervals, to allow the iterative development of themes and to decrease lone researcher bias. The developing themes were reviewed and discussed further with JC and JD. A formal framework was deliberately not applied; the focus of the analysis was first on the subjective experiences of the participants, and then on the key interactions with healthcare professionals (HCPs) in relation to end of life care decision-making. ${ }^{18}$

\section{FINDINGS}

\section{Study population}

Recruitment began following ethical approval in January 2016. Seventeen parents of 11 children participated in 
Table 1 Interview schedule

\begin{tabular}{ll} 
Open questions & Prompts \\
\hline $\begin{array}{l}\text { Demographics and introduction } \\
\text { Check understanding of what the }\end{array}$ & Do you have any questions? \\
interview is about &
\end{tabular}

About child and family

Please can you start by telling me about (child's name) and your family?
Were you aware that (child) was unwell before they were born?

When was (child) diagnosed? (where were they at this time-home, hospital, PICU) What was that like for you and your family?

At that point did you know that (child's) life would be limited?

What plans or decisions were made at this point about their care?

Who was involved?

What were your wishes and fears at this time?

\section{Child becoming ill and time on PICU Can you tell me about when (child) became poorly and went to hospital and PICU?}

\section{Decision making and planning on PICU: general}

When (child) was being cared for on PICU, can you tell me about your experiences of decision making and planning for their care in the future?

EOLC/PC decisions, ACP and
planning on PICU
When did you realise/understand that
(child) was going to die?

\section{ACP specific}

When (child) was on PICU did you/ were you offered the chance to complete an ACP?

What was that like?/How did you feel?

Did you have plans or discussions about (child's) admission to PICU?

How many times did they come to PICU?/How long were they on PICU? What were your wishes and fears at this time?

What decisions?/Who initiated?/Discussion?/Who made final decision?/Were you involved? How?/Timing/Feelings

Plans made? You?/Medical team(s)/Together?/formal or informal?/Timing/Feelings Did you have any wishes or fears about decisions being made or planning about (child's) care at this time?

Did you make plans for their end of life care?

At this point did you have any idea about what 'end of life care' might mean or what it might look like?

What were your wishes and fears at this time?

Was a decision made to limit treatment/withdraw active treatment, for example, taking the tube out?

How was this decision made?

Did you know what it was?

What was the process like?/How did it feel?

Did it get reviewed at any time?

What do you think was the most useful thing about the ACP? Were there any problems with using one?

What were your hopes and fears at this time?

If not:

Do you know what an ACP is?

Do you think you would have liked to have been offered the opportunity to complete one?

Do you think you would have used it?

What do you think would be the most useful thing about an ACP document? What do you think might be the problems with an ACP?

$\begin{array}{ll}\text { Around time of death and beyond } & \text { What was most important to you at this time? } \\ \text { Do you feel able to describe what } & \text { Who was there? Had this been planned previously? What decisions about who was } \\ \text { happened when (child) died? } & \text { present did you make? } \\ & \text { Who helped you or supported you? } \\ & \text { Did time/planning/discussions influence the decisions made? How? } \\ & \text { Are there any plans/decisions that you would make differently? } \\ & \text { Is there any advice that you would give other parents facing a similar situation in the } \\ & \text { future? }\end{array}$

$\mathrm{ACP}$, advanced care plan; EOLC, end of life care; $\mathrm{PC}$, palliative care; $\mathrm{PICU}$, paediatric intensive care unit.

a total of 11 interviews. The sample characteristics are outlined in table 2. Together for Short Lives categories are outlined in table 3 .

\section{THEMES}

Five overarching, inter-related themes were identified:
1. Parents have significant knowledge and experiences that influence the decision-making process.

2. Trusted relationships with HCPs are key to supporting parents making end of life decisions.

3. Verbal and non-verbal communication with HCPs impacts on the family experience. 
Table 2 Sample characteristics

\begin{tabular}{|c|c|c|c|c|}
\hline Family & $\begin{array}{l}\text { Participants } \\
\text { (mother (M)/father (F)) }\end{array}$ & Time since bereavement & Age of child & $\begin{array}{l}\text { Child's diagnosis/ } \\
\text { Togetherfor Short Lives } \\
\text { category }^{2}\end{array}$ \\
\hline 1 & $\mathrm{M}$ and $\mathrm{F}$ & 1 year 6 months & 3 years & 3 \\
\hline 2 & $\mathrm{M}$ and $\mathrm{F}$ & 9 months & 6 months & 4 \\
\hline 3 & M & 5 months & 5 months & 3 \\
\hline 4 & $\mathrm{M}$ and $\mathrm{F}$ & 8 months & 11 years & 1 \\
\hline 5 & $\mathrm{M}$ and $\mathrm{F}$ & 1 year 7 months & 2 years 11 months & 1 \\
\hline 6 & M & 1 year 7 months & 9 months & 1 \\
\hline 7 & $\mathrm{M}$ and $\mathrm{F}$ & 10 months & 18 years & 1 \\
\hline 8 & M & 1 year 1 month & 5 months & 4 \\
\hline 9 & $\mathrm{M}$ and $\mathrm{F}$ & 7 months & 16 years & 4 \\
\hline 10 & M & 1 year 11 months & 2 years & 1 \\
\hline 11 & M & 10 months & 1 year 11 months & 4 \\
\hline
\end{tabular}

4. Engaging with end of life care decision-making can be emotionally overwhelming, but becomes possible if parents reach a 'place of acceptance'.

5. Families perceive benefits to receiving end of life care for their child in a PICU.

Parents have significant knowledge and experiences that influence the decision-making process: "I may not have the practical skills that the nurse has, but my knowledge of my child and my child's illness far surpasses that"

Parents had intimate knowledge of their child as a person and significant expertise related to their child's condition. They frequently used medical slang and jargon during the interviews, such as 'her blood pressure was in her boots' '(oxygen) sats'and 'oscillated again'. Having seen how clinical measurements, blood test results and other investigations were used in medical decision-making, they referred to numerical measurements to provide some certainty: towards the end once we'd really got into the grips of treatment, you know, we understood our kids blood work, you know, literally like breathing and everything that's going on... we automatically look at blood work and know what's going on (Mother 10)

Almost all parents had experienced several serious episodes of dramatic deterioration in their child's condition, during which they had gained detailed knowledge of high-intensity, specialised treatments. These experiences shaped and influenced their hopes and expectations for the medical management that would be provided for their child:

... about a week before we kept saying (Child 11) probably could do with going onto (intervention) but there was another child on (intervention) at that time and ... so we were sort of waiting, umming and arring over the (intervention) ... I remember (child's

Table 3 Together for Short Lives categories

\section{Category}

1. Life-threatening conditions for which curative treatment may be feasible but can fail

\section{Conditions where premature death is} inevitable

\section{Description}

Access to palliative care services may be necessary when treatment fails or during an acute crisis, irrespective of the duration of threat to life. On reaching long-term remission or following successful curative treatment there is no longer a need for palliative care services.

Examples: cancer, irreversible organ failures of heart, liver, kidney.

There may be long periods of intensive treatment aimed at prolonging life and allowing participation in normal activities.

Examples: cystic fibrosis, Duchenne muscular dystrophy.

\section{Progressive conditions without curative Treatment is exclusively palliative and may commonly extend over many years.} treatment options Examples: batten disease, mucopolysaccharidoses.

4. Irreversible but non-progressive conditions causing severe disability, leading to susceptibility to impaired health
Children can have complex healthcare needs, a high risk of an unpredictable lifethreatening event or episode, health complications and an increased likelihood of premature death.

Examples: severe cerebral palsy, multiple disabilities, such as following brain or spinal cord injury. 
father) saying at the time 'but we told you days ago' (Mother 11)

Parental decisions related to their child receiving high-intensity treatments could also be influenced by a sense that there was 'nothing to lose', when the alternative was that their child would almost certainly die:

if we leave the child as she is, she's going to pass away anyway. But if we do the, if we put her on the machine there's a chance that she's going to have a problem said well it's a no brainer, you know. What's the point? You know, if you're going to leave her, she's going to pass away anyway. You might as well on the machine, what have you got to lose? (Father 9)

Clinical uncertainty was a common experience and was particularly confusing and difficult for parents when they were used to making decisions based on precise medical explanations and test results. In this situation, parents hoped for consensus among their HCPs:

You couldn't help but feel-not quite them and us, but was more-it was case where you thought, 'Are they all on the same page?' Well, they probably were on the same page.... But if they're not, we've got a fight on our hands ... (Father 4)

Parents' expertise extended to the ability to recognise that their child was dying when that time came. Many of the parents described recognising that their child was dying before any open conversations had occurred with HCPs about this. Frequently, there was a tacit realisation, knowing "in my heart", or having a feeling that "she just wasn 't right". For some, the realisation was associated with seeing their child's increasing dependence on life-sustaining interventions:

Because there was really nothing and there was no improvement whatsoever ... The machine got knocked and ... it was only for a second, it just jumped in and his blood pressure crashed down low and his heart rate got down very low and, off literally just for a second (Mother 4)

For others, it was a realisation that their child's condition was deteriorating despite the treatments that they were receiving:

... you then don't necessarily need to be a doctor to understand that you're on a bit of a one-way street (Father 1)

If I'm honest, the moment they ventilated her, I think deep down we knew she wasn't coming back that time. ... I didn't want to say it out loud and I didn't want to admit it, but I think that we all knew (Mother 10)

Trusted relationships with healthcare professionals are key to supporting parents making end of life decisions: "I've got to admit they went a little bit above and beyond their duties"

Trusted relationships with HCPs were highly valued. Continuity of care was a key factor underpinning the development of such relationships. Parents often identified, by name, the individuals who they particularly trusted. These were often HCPs from PICU but were also members of other teams involved in their child's care. Such HCPs had usually advocated for the child or the parents at difficult times and offered extra support, such as providing a personal contact number or going into work on a day off to see the child and family:

So he gave me his mobile number, so 'Just text me or something and I'll make sure that one of my team would come down and see you and then we'll make sure that she's getting the right sort of ....' That was really very kind of the (Doctor) to do that and that made life a lot easier for us, a lot easier for everybody (Father 9)

These individuals were particularly important at times when key decisions were being made.

He was very good at explaining things, he was and he would answer any questions ... from my perspective when he was telling us 'I'm very sorry. There's nothing else that we can do.' And then it was believable, I didn't feel like we're being fobbed off, or anything like that (Father 4)

Parents recognised that these HCPs had their own emotions and stresses to cope with, and empathised with how this affected them.

the doctor that helped us at the end was lovely. ... Couldn't have asked for a better doctor and it turns out that unfortunately five people died on (intensive care) that day. So he had a bad day (Father 7)

Relationships with HCPs were fragile and trust was easily compromised. Parents described occasions when they were provided with conflicting advice as difficult:

one would be happy to do something or they'd put him on something. And then another one would come in and say, 'now take him off that...' so that was where we found it a bit hard-it's different (Mother 4)

it's a great idea to have one consultant that will oversee because there's so many doctors in-out, in-out, in-out, you know, and obviously everybody's got different opinions as to how things should be done. I think for (Child 10) she would have really benefited from having one person that had one say (Mother 10)

One mother described how her trust was compromised when she discovered that a meeting had been held about her child's care without her involvement; "you have broke [n] my trust again completely" and "don't lie to me" (Mother 9). It also happened when parents discovered that an aspect of their child's medical treatment was not being openly discussed with them: 
It's that trust relationship, you trust so openly because your consultants, doctors, registrars, nurses, these are like Gods and you're looking at them and thinking come on, I know this happened. It doesn't change what's happened, we know that (complication)'s part and parcel and this is a risk, we know. (Mother 10)

Trust was also compromised if parents felt that they were not being listened to or felt that they had to repeat their concerns over and over to many members of staff:

you're having to explain what (the child's condition) is, and it becomes 'groundhog day' that you're doing it over and over again. (Mother 6)

Verbal and non-verbal communication with healthcare professionals impacts on the family experience: "somebody needs to sit with you and explain why you can't have this or why you can't have that"

Parents described their experiences of receiving information both at the bedside, and during more formal meetings. Both verbal and non-verbal communication made a difference to parents. In terms of verbal communication, parents described how important it was for information to be presented in a clear and sometimes brutally honest fashion. It helped if this information was given by a trusted HCP, but that sometimes depended on the uncertainties of the shift roster:

I always asked her from the beginning if I'm looking at mortality, then tell me. And a few nights before the end, she said, 'You're looking at it'. So yes, but that was more to do with kind of-I don't know, good luck or whatever you want to put in that. It might not have been her, if it would have been someone else, I wouldn't have had that at all. (Mother 6)

Meetings to discuss end of life care with the clinical team were challenging experiences for parents. They were frequently outnumbered by an 'overwhelming' number of staff which they interpreted as an indication of the severity of the situation:

(Child 4) was very popular with the staff in the hospital and so a lot of people took an interest in him. They just wanted to be there at that meeting and we very much appreciate them wanting to do that. But I think it was a bit disconcerting. (Father 4)

Parents' described a realisation that their child was dying informed by actions rather than explicit communication, such as a move to particular area of PICU or being given priority to use the parent's bedroom:

And we moved over to (letter) side; that was awful. Because there you're surrounded by a lot of other sick children and then you think, 'Well, that must mean (child 3)'s really sick as well' (Mother 3)

And so when she (nurse) came over ... I said 'oh I'm sorry, I've left all my stuff in the parents' bedroom, I'll get it out in a sec so you can use it' and she said 'oh no, no, nobody's using it'.... and she said 'nobody's need is greater than yours today' and I thought 'shit'. And just hearing that, I thought 'oh hang on, so you're telling me basically I've got the sickest child on the unit'. And it was a bit of a wake-up call (Mother 11)

One parent described a palpable shift in the manner in which HCPs spoke to her as her child was dying:

my relationship with all the consultants on the unit shifted and they all of a sudden became very business-like and very, how I'd seen them with other parents but never with me. It had always been quite a chatty friendship almost and very comfortable with each other, chatting to people. And now they were very matter of fact, very focused and very negative. So Sunday morning we're all stood round the bed and each and every one of them are just looking at (Child) with this grave look on their face and they're clearly all upset, shocked and uncomfortable ... So I found them quite difficult and quite brutal really even though I could see why they were doing it....... They were all of a sudden now, a bit like barriers were going up and they were stepping back from, like 'we can't be chatting, we can't be your friend now, we've got a job to do and we need to focus on this'. (Mother 11)

\section{Engaging with advance care planning can be emotionally overwhelming, but becomes possible if parents reach a 'place of acceptance'}

Parents experienced wide-ranging, intense emotions towards the end of their child's life, which impacted on their ability to take part in end of life care decision-making. They described a range of conflicting emotions related to a hope that their child would not suffer, and a simultaneous fear that their child was going to die. These emotions created stress, anxiety, a state of inner conflict and cognitive dissonance.

Parents felt intensely vulnerable as their children approached the end of life. They described feeling 'mentally worn down' and 'not being able to think straight', as below:

looking back, I realise just how, you know, mentally worn down with an overload of information I was because I remember them asking me to sign the consent form for the (treatment) and I was looking at the form and ... my mind had just completely gone ... I just couldn't physically remember how to sign my own name (Mother 10)

It was such a busy few hours that morning. And the noise was incredible. And it probably wasn't any more noisy than normal, but it felt massively noisy. I just, probably because I was just exhausted and I'd had sleeping tablets and I think I was still recovering from them and I couldn't think straight about anything. ... And then the next significant thing was they said 'we need to go and have a chat. (Mother 11) 
In these contexts, end of life care decision-making could feel overwhelmingly difficult for parents, particularly when they were being asked to make decisions about the withdrawal of life-sustaining treatments:

I think the hard thing was that, you know, they were kind of, like, 'what do you think?', which is great that they wanted to ask our opinion but, at the time, we were like so overwhelmed. And I remember thinking, why are they asking us! No, I understand it's good to give parents that power but I was like, you know, 'I have no idea, they're the experts' (Mother 8)

Clear guidance and the support of trusted clinicians was critical. The manner in which parents were engaged in the decision-making process was important, for example, feeling that they have made a choice to 'say goodbye'rather than having to make a choice to withdraw life-sustaining treatments.

that decision didn't come about easy. It didn't-people think oh well, you chose to switch his life support off. Yeah, we did but we also chose to say, we had to choose to say goodbye to him, you know what I mean? (Father 5)

So while I know it comes under sort of end of life decision, it didn't feel like we were having to decide whether he'll live or not. It was more about agreeing that it was time to stop, which I think was the right way to do it. All the way through this, we've been led by the medical teams (Father 4 )

There was some comfort in making decisions that they considered to be 'best' for their child.

As much as it did hurt us to let him go, we were thinking what was best for him to be comfortable and not in pain (Mother 2)

The need to preserve their role as parents, providing love and care for their child, was strongly apparent in their accounts. One parent described how much she valued being given the opportunity to hold her child:

all you can see is that your child is just hooked up to everything possible and they made my day when they lifted her up once she was-because she was relatively flat with all the drugs and what not—and lifted her up so I could actually have a cuddle and put her on me. Oh, even now, I'm so grateful that they did that (Mother 10)

Some parents expressed a desire to know what to expect when it came to their child dying, although they appreciated that this may not be something that other parents would want:

...not knowing what death is and what it's going to look like... when you're seeing it for the first time, when you're kind of dealing with it, both as an experience of death but also as your baby... I would like to have known that...sorry ... Not everybody would... (Mother 6)

Where parents felt they were missing crucial information, they sought it out from other parents:

We did need to know what happened if we switched the machines off. And so I did ask another parent about what happened to their friend when at the hospital, because I wanted to imagine that scenario if it was going to happen ... (Mother 1)

Not all of the parents were aware of ACP, and many had not experienced this for their child. There were opposing views, with some parents feeling that $\mathrm{ACP}$ 'would have been very useful, and others that a plan which considered the child's death was not acceptable; 'never an option'. Parents reported that the timing of conversations with respect to ACP was important, but could be particularly difficult where there was uncertainty about the likely outcome of a treatment or procedure, such as surgery or a new medical intervention:

We knew that his life would be short ... but we never planned for a negative, we always planned for positives. I don't think anybody told us the potential negative of that (intervention) and I don't think they knew the potential negatives that could happen because they weren't expecting that to happen (Father 7)

Parents described the need to be in a "place of acceptance' in order for ACP conversations to take place:

I think you have to come to a place yourself to kind of accept what's going to happen. And until you've got to that acceptance, I think it can make people very aggressive. ... And for me, I kind of accepted that was it at that point. (Mother 6)

Parents who had made a formal ACP for their child made practical suggestions related to the information and knowledge that should be considered for parents in order for them to make an informed decision about whether to create an ACP. They suggested that it was necessary to observe and understand the implications of particular interventions, such as ventilation, before considering this in an ACP:

it'd be nice to have that little bit of a tick box 'Has the parent seen a ventilator?' I know they've made this decision but you know like when you have at the end, 'cause some just don't want anything, and that's fine and some have just the oxygen. Some want IVs, you know you've got that little paragraph at the bottom, so just underneath it you know, it would be nice 'Have they seen it?' and at least then you'll know. And maybe then that's the time when the consultant will say 'Would you like to see it?' you know just, we can do a little session for you where you can go in and have a look (Mother 9) 
Families perceive benefits to receiving end of life care for their child in a PICU: "the support that we received on (PICU) was just amazing"

The parents all provided poignant accounts of their child's death. Some were shocking and traumatic, for example, when they witnessed resuscitation as their child's terminal event:

And then I think for me the last straw was when the last time they were doing the (cardiopulmonary resuscitation) CPR, is when the guy came with the drill and he started to put a drill in her (Father 9)

then at some point we knew they'd been working for ages, they were going at it and then I heard one of them crack a rib ... we'd obviously heard that and we knew that there's no way her chest was coming back from that, she was struggling already and it's not their fault, it happens, you know, it is what it is (Mother 10)

However, even in these traumatic circumstances, parents valued the reassurance provided in PICU that all possible treatment options had been explored for their child:

There was nothing that they could do for him and they had made that clear-they'd tried everything. They even tried things they thought weren't going to work (Mother 2)

By this time I knew a lot of what was goes on in the unit and I knew that (intervention) wasn't a good place to be. I knew that I hadn't seen many kids come off (intervention) and go home but, at the same time, I thought well it's worth a try and I also knew if they didn't think it was worth doing, they wouldn't have done it. It's expensive. And I know you can't put a price on life, can you, but I knew that they wouldn't have tried that unless there was a chance (Mother 11)

Being in PICU and having more days of life than might have been possible in other clinical settings was also highly valued:

we had (doctor) worked several nights through with her, where he didn't leave her bedside for lines and things like that; of which in hindsight, she was going to go anyway. But by doing that, he gave me an extra couple of days of which, if we'd gone to a hospice you can't do things like that. She would have just gone. So for me, I wouldn't have wanted that (Mother 6)

\section{DISCUSSION}

\section{Summary}

This study provides important insights into the experiences of end of life care decision-making of parents of children with life-limiting and life-threatening conditions who die in a PICU. The study has identified important themes that affected their experience. The parents who participated in this study had expert knowledge of their child and their child's condition, and wanted this to be taken into account in medical decision-making. Parents were often aware that their child may be dying before this was openly acknowledged by their HCPs. Trusted relationships with HCPs were critical to their experience of end of life care decision-making, as were both verbal and non-verbal communication. Every situation was unique; making decisions about care at the end of a child's life was described as 'overwhelming' by some. The parents in this study expressed a preference for end of life care discussions to be conducted by a trusted HCP in small meetings.

Parents described the need to have come to a "place of acceptance' in order to be able to take part in end of life care decisions. The idea of an ACP was received positively by some parents, but was completely unacceptable, even in principal, to others. The end of life was traumatic for parents to witness if associated with attempts at resuscitation and invasive medical procedures, however the continuity of care provided in PICU, reassurance that all possible treatment options had been tried for their child, and the extra hours of life that could be provided were all perceived as important benefits by parents.

\section{Strengths and limitations}

Recruiting to research about end of life care in children is known to be challenging. ${ }^{19}$ The study was conducted with parents whose children had died from a diverse range of life-limiting conditions. However, the number of participants is relatively small, and they were all recruited through the same PICU which may limit the generalisability of the findings. While data saturation was reached around the key themes reported here, it is likely that the parents who felt unable to participate may have had views, experiences and perceptions that were different. There were several emerging themes in our data analysis which are not reported here, including the experience of end of life care meetings, the care of siblings, spiritual needs and bereavement care; all are worthy of further research. Furthermore, the study's findings are based on retrospective accounts that may have been reframed over time. We did not capture the experiences and perceptions of families who are currently in the process of making end of life care decisions for their children, or the views of any children or young people regarding their own end of life care decision-making.

\section{Comparison with existing literature}

There is a lack of empirical research examining end of life care decision-making in PICU, perhaps because admission to PICU does not tend to be explicitly for end of life care.$^{20}$ Our findings contrast with previous research that suggested an awareness among HCPs that a child may be dying before this is recognised by their parents. ${ }^{21}$ In keeping with our finding that parents often had an unspoken knowledge that their child was dying, there are published case studies and parental narratives which also suggest an earlier recognition among parents. ${ }^{22}{ }^{23} \mathrm{~A}$ 
situation of 'mutual pretence' may be reached between parents and HCPs, where this knowledge is unspoken; this situation of mutual pretence could potentially be acknowledged more openly in order to start discussions about palliative and end of life care, including referral to specialist paediatric palliative care services, where available. ${ }^{24}$

Previous studies have described influences on parental decision-making as the child's diagnosis, prognosis and the extent of their pain, discomfort or suffering. ${ }^{21}{ }^{25}$ Our findings indicate that clinical uncertainty, unpredictable outcomes of treatments, a sense of loss of control, and the intense emotional burden that can exist for both parents and HCPs add to the complexity of end of life care decision-making in PICU. As medical treatments advance, and information about such treatments becomes more available particularly in media reports, these clinical and ethical complexities are becoming ever more prominent. In this context, for parents who may already be finding it difficult to understand that their child's condition is incurable, ${ }^{26}$ conversations about end of life care may represent a significant change from previously cure-focussed management plans. Previous research has suggested that parents do not always need to fully acknowledge their child's situation in order to place emphasis on the relief of suffering. ${ }^{21}$ It may therefore be possible to reach a situation earlier on in a child's illness which provides the opportunity for conversations about end of life care, ACP or referral to specialist paediatric palliative care services, through skilful acknowledgement of uncertainty and the conflicting emotions that parents may be experiencing, including fear and hope.

Parents value affirmation in their decision-making from a HCP who is known and trusted and who has witnessed the magnitude of their child's illness. ${ }^{27}$ Trusted relationships with HCPs were critical to the experience of the parents in this study as they tried to make decisions which were 'best' for their child. Continuity of care, and a visible commitment to understanding and addressing the end of life care needs of the child and their family, were important in achieving such relationships. In keeping with previous studies, there were times when conflicting advice brought about through changes in staff could cause parents to feel confused and abandoned. ${ }^{28}$ Provision of a working environment that allows for continuity of care warrants attention, as does care for the workforce as they face these emotionally charged, ethically challenging situations with children and their families.

Parents were reassured by the knowledge that all possible treatment options had been explored for their child, and valued the extra days of life provided by the delivery of high intensity treatments in PICU. Given the rising numbers of children with life-limiting and life-threatening conditions and the complexity of their needs, there is a need to consider how this care and associated reassurances can be offered to children in environments other than PICU, including high dependency units, and children's hospices. There is a careful and highly individual balance to be found for each family between the knowledge that everything possible has been tried for their child, alongside preparation for the time when high intensity treatments may become futile and potentially harmful towards the end of a child's life. ${ }^{29}$

\section{Recommendations}

Wider recognition of the complex factors that relate to end of life care decision-making in PICU, and an organisational commitment to providing a clinical environment in which continuity can be provided to families, could both assist with the implementation of policy guidance related to end of life care decision-making.

An important area for research is further investigation into the child and family perspectives of ACP, and the impact of earlier integration of palliative care into a child's care. A recent study suggested that children who received specialist paediatric palliative care were five times less likely to receive high intensity treatments at the end of their lives. ${ }^{30}$ Another study examined the potential impact of routine referral to such services when a child was commenced on extracorporeal life support in PICU. ${ }^{31}$ This approach to the introduction of specialist paediatric palliative care could be further explored. However, these specialist services are inconsistently funded and provided both in the UK and internationally ${ }^{10}$; ACP and end of life care decision-making therefore depends on the principles of palliative care being practised among the wider workforce.

There is more work to be done to understand how end of life care can be effectively achieved in PICU for individual children and families. Future research into the views of children regarding their own end of life care decision-making and ACP, as well as research to further understand the experiences of families who are currently in the process of making end of life care decisions for their children would be of value.

\section{CONCLUSION}

Learning from the experiences and perceptions of families should inform improved policy and practice. This study highlights the need for recognition of parental expertise and experience, and the critical importance of a trusted relationship between families and their HCPs, which can often be established through repeated admissions or prolonged stays in PICU. While trust is vital to the relationships between families and HCPs, it is also fragile, and can be easily lost. Parents are highly vulnerable and may be exhausted, confused and uncertain at the times when they are asked to engage with end of life care decision-making. Earlier acknowledgement of clinical uncertainty and the conflicting emotions that parents may be experiencing could help in earlier discussions about end of life care and introduction to specialist paediatric palliative care services, where available.

The needs of each family and their readiness for involvement in decision-making is highly individual. ACP 
is not well understood by parents, and appears to be more helpful for some than others. End of life care of a child on PICU provides potential benefits from a family perspective, and there is a need to consider how the care and reassurances they perceive can be provided in other environments. There is also a pressing need for greater understanding of the child's experience, which should be the focus of further research.

\section{Author affiliations}

${ }^{1}$ Warwick Medical School, University of Warwick, Coventry, West Midlands, UK

${ }^{2}$ Paediatric Intensive Care Unit, Birmingham Women's and Children's NHS

Foundation Trust, Birmingham, Birmingham, UK

${ }^{3}$ School of Health Sciences, University of Nottingham, Nottingham, Nottinghamshire, UK

${ }^{4}$ Warwick Medical School, University of Warwick, Coventry, West Midlands, UK

Contributors The study was conceptualised by SM, AP, JC and JD, informed and guided by Patient and Public Involvement, with specific guidance and advice provided by EH. JS conducted the interviews. AP managed the conduct of the study. SM, JLS and AP drafted the article with contributions from JC and JD. EH acted as PPI coauthor and reviewed the article to ensure relevance to the family situation. JC and JD reviewed the article for intellectual content and edited the final version. All authors reviewed, edited and agreed this version.

Funding This work was supported by Birmingham Children's Hospital Research Foundation, grant number: BCHRF-369.

Competing interests None declared.

Patient consent for publication Not required

Ethics approval Ethical approval was granted on 5 January 2016 by the East Midlands Research Ethics Committee IRAS No: 184171 REC 15/EM/0539. Amendment 1.0.1 was approved on 31 May 2016.

Provenance and peer review Not commissioned; externally peer reviewed.

Data sharing statement The research protocol is available as a supplementary file (supplementary file 1). The data that support the findings of this study are not publicly available due to their containing information that could compromise the privacy of the research participant.

Open access This is an open access article distributed in accordance with the Creative Commons Attribution Non Commercial (CC BY-NC 4.0) license, which permits others to distribute, remix, adapt, build upon this work non-commercially, and license their derivative works on different terms, provided the original work is properly cited, appropriate credit is given, any changes made indicated, and the use is non-commercial. See: http://creativecommons.org/licenses/by-nc/4.0/.

\section{REFERENCES}

1. Fraser LK, Miller M, Hain R, et al. Rising national prevalence of lifelimiting conditions in children in England. Pediatrics 2012;129:e92 3-e929.

2. Together for Short Lives. Children's Palliative Care Definitions. https://www.togetherforshortlives.org.uk/changing-lives/supportingcare-professionals/introduction-childrens-palliative-care/categoriesof-life-limiting-conditions/

3. Sidebotham P, Fraser J, Fleming $P$, et al. Patterns of child death in England and Wales. Lancet 2014;384:904-14.

4. Confidential Enquiry into Maternal and Child Health. Why Children Die: a pilot study (2006. London: CEMACH, 2008.

5. Ramnarayan P, Craig F, Petros A, et al. Characteristics of deaths occurring in hospitalised children: changing trends. J Med Ethics 2007;33:255-60.
6. McCallum DE, Byrne P, Bruera E. How children die in hospital. J Pain Symptom Manage 2000;20:417-23.

7. Plunkett A, Parslow RC. Is it taking longer to die in paediatric intensive care in England and Wales? Arch Dis Child 2016;101:798-802

8. News BBC. Charlie Gard: The story of his parents' legal fight. 2017 https://www.bbc.co.uk/news/health-405544622017.

9. News BBC. Alfie Evans: Legal battle toddler dies. 2018. https://www. bbc.co.uk/news/uk-43933056.

10. Knapp C, Woodworth L, Wright M, et al. Pediatric palliative care provision around the world: a systematic review. Pediatr Blood Cancer 2011;57:361-8.

11. Mullick A, Martin J, Sallnow L. An introduction to advance care planning in practice. BMJ 2013;347:f6064.

12. Lotz JD, Jox RJ, Borasio GD, et al. Pediatric advance care planning: a systematic review. Pediatrics 2013;131:e873-e880.

13. National Palliative and End of Life Care Partnership (2015). Ambitions for Palliative and End of Life Care: A national framework for local action. 2015. http://endoflifecareambitions.org.uk/wpcontent/uploads/2015/09/Ambitions-for-Palliative-and-End-of-LifeCare.pdf.

14. National Institute for Health and Care Excellence (NICE). NICE Guideline NG61 (2016) End of Life Care for Infants, Children and Young People. https://www.nice.org.uk/guidance/ng61.

15. Villanueva G, Murphy MS, Vickers D, et al. End of life care for infants children and young people with life limiting conditions: summary of NICE guidance. BMJ 2016;2016:i6385

16. Longden JV. Parental perceptions of end-of-life care on paediatric intensive care units: a literature review. Nurs Crit Care 2011;16:131-9.

17. Braun V, Clarke V. Using thematic analysis in psychology. Qual Res Psychol 2006;3:77-101.

18. Flick U. The SAGE Handbook of Qualitative Data Analysis. London: SAGE Publishing, 2013

19. Hudson BF, Oostendorp LJ, Candy B, et al. The under reporting of recruitment strategies in research with children with life-threatening illnesses: A systematic review. Palliat Med 2017;31:419-36.

20. Namachivayam P, Shann F, Shekerdemian L, et al. Three decades of pediatric intensive care: Who was admitted, what happened in intensive care, and what happened afterward. Pediatr Crit Care Med 2010;11:549-55.

21. Wolfe J, Klar N, Grier HE, et al. Understanding of prognosis among parents of children who died of cancer: impact on treatment goals and integration of palliative care. JAMA 2000;284:2469-75.

22. Nimmo S. Letting my daughter go. BMJ 2018;360:j5771.

23. Darnill S, Gamage B. The patient's journey: palliative care-a parent's view. BMJ 2006;332:1494-5.

24. Bluebond-Langner M. The Private worlds of Dying Children. USA: Princeton University Press, 1978

25. Meyer EC, Burns JP, Griffith JL, et al. Parental perspectives on end-of-life care in the pediatric intensive care unit. Crit Care Med 2002;30:226-31.

26. Björk M, Sundler AJ, Hallström I, et al. Like being covered in a wet and dark blanket - Parents' lived experiences of losing a child to cancer. Europ J Onc Nurs 2016;25:40-5.

27. Sullivan J, Monagle P, Gillam L. What parents want from doctors in end-of-life decision-making for children. Arch Dis Child 2014;99:216-20.

28. Melin-Johansson C, Axelsson I, Jonsson Grundberg M, et al. When a child dies: parents' experiences of palliative care-an integrative literature review. J Pediatr Nurs 2014;29:660-9.

29. Mitchell S, Dale J. Advance Care Planning in palliative care: a qualitative investigation into the perspective of Paediatric Intensive Care Unit staff. Palliat Med 2015;29:371-9.

30. Widger K, Sutradhar R, Rapoport A, et al. Predictors of specialized pediatric palliative care involvement and impact on patterns of endof-life care in children with cancer. J Clin Oncol 2018;36:801-7.

31. Doorenbos AZ, Starks H, Bourget E, et al. Examining palliative care team involvement in automatic consultations for children on extracorporeal life support in the pediatric intensive care unit. $J$ Palliat Med 2013;16:492-5. 